University of Nebraska - Lincoln

DigitalCommons@University of Nebraska - Lincoln

Biological Systems Engineering: Papers and

Publications

Biological Systems Engineering

May 2008

\title{
Artificial Neural Network estimation of soil erosion and nutrient concentrations in runoff from land application areas
}

\author{
Minyoung Kim \\ National Institute of Agricultural Engineering, Rural Development Administration, 249 Seodun-dong, \\ Gwonson-gu, Suwon 441-707, Republic of Korea \\ John E. Gilley \\ University of Nebraska-Lincoln, john.gilley@ars.usda.gov
}

Follow this and additional works at: https://digitalcommons.unl.edu/biosysengfacpub

Part of the Biological Engineering Commons

Kim, Minyoung and Gilley, John E., "Artificial Neural Network estimation of soil erosion and nutrient concentrations in runoff from land application areas" (2008). Biological Systems Engineering: Papers and Publications. 15.

https://digitalcommons.unl.edu/biosysengfacpub/15

This Article is brought to you for free and open access by the Biological Systems Engineering at DigitalCommons@University of Nebraska - Lincoln. It has been accepted for inclusion in Biological Systems Engineering: Papers and Publications by an authorized administrator of DigitalCommons@University of Nebraska Lincoln. 


\title{
Artificial Neural Network estimation of soil erosion and nutrient concentrations in runoff from land application areas
}

\author{
Minyoung Kim ${ }^{a, *}$, John E. Gilley ${ }^{b}$ \\ a National Institute of Agricultural Engineering, Rural Development Administration, 249 Seodun-dong, \\ Gwonson-gu, Suwon 441-707, Republic of Korea \\ b USDA-ARS, Agroecosystem Management Research Unit, 120 Keim Hall, East Campus, University of Nebraska, \\ Lincoln, NE 68583-0934, USA
}

\section{A R T I C L E I N F O}

\section{Article history:}

Received 26 July 2007

Received in revised form

15 May 2008

Accepted 21 May 2008

\section{Keywords:}

Artificial Neural Network (ANN)

Soil erosion

Land application

Manure runoff

Nutrient losses

Nitrogen

Phosphorus

Water quality

\begin{abstract}
A B S T R A C T
The transport of sediment and nutrients from land application areas is an environmental concern. New methods are needed for estimating soil and nutrient concentrations of runoff from cropland areas on which manure is applied. Artificial Neural Networks (ANNs) trained with a backpropagation (BP) algorithm were used to estimate soil erosion, dissolved P (DP) and $\mathrm{NH}_{4}-\mathrm{N}$ concentrations of runoff from a land application site near Lincoln, Nebraska, USA. Simulation results from ANN-derived models showed that the amount of soil eroded is positively correlated with rainfall and runoff. In addition, concentrations of DP and $\mathrm{NH}_{4}-\mathrm{N}$ in overland flow were related to measurements of runoff, EC and $\mathrm{pH}$. Coefficient of determination values $\left(R^{2}\right)$ relating predicted versus measured estimates of soil erosion, DP, and $\mathrm{NH}_{4}-\mathrm{N}$ were $0.62,0.72$ and 0.92 , respectively. The ANN models derived from measurements of runoff, electrical conductivity (EC) and $\mathrm{pH}$ provided reliable estimates of DP and $\mathrm{NH}_{4}-\mathrm{N}$ concentrations in runoff.
\end{abstract}

Published by Elsevier B.V.

\section{Introduction}

Excessive land application of manure can impair water quality by introducing pollutants including sediment and nutrients (USEPA, 2000). Physical, chemical, and biological damages caused by sediment and nutrients in runoff from land application areas in North America have been estimated to cost approximately $\$ 16$ billion annually (National Research Council Committee on Animal Nutrition, 1993).

Recent attention has been focused on developing methods to minimize water quality impacts associated with the land application of manure to agricultural areas (Sharpley et al., 1994). Manure management programs are being developed to enhance crop production while minimizing environmental concerns. Accurate estimates must be made of the quantity of nutrients contained in manure and the rate at which those nutrients become available following application. Currently, farmers are encouraged to apply manures based on crop phosphorus $(\mathrm{P})$ requirements, as opposed to nitrogen $(\mathrm{N})$ needs (Soil Conservation Service, 1994).

Soil erosion by water occurs as a result of the detachment of soil particles by raindrops and runoff. Transport of

\footnotetext{
* Corresponding author. Tel.: +82 31290 1985; fax: +82 312901945.

E-mail address: mykim75@rda.go.kr (M. Kim). 0168-1699/\$ - see front matter. Published by Elsevier B.V. doi:10.1016/j.compag.2008.05.021
} 
particles by splash and shallow flowing water leads to impairment of water quality. Practices to control erosion have been developed including conservation tillage, reduction of slope length (contouring, contour strip cropping and terraces), and the use of hydraulic structures (grassed waterways, gradecontrol structures, terraces, and water and sediment control basins) (Czapar et al., 2005). Along with these practical guidelines, prediction tools for soil erosion have been developed including the Universal Soil Loss Equation (USLE) (Wischmeier and Smith, 1978), the Revised USLE (RUSLE) (Renard et al., 1997) and the Water Erosion Prediction Project model (WEPP) (Lane and Nearing, 1989). Both USLE and RUSLE equations consist of empirical model sets derived from an extensive database and their model parameters contain uncertainty when using these equations for a specific area (Renard and Freimund, 1994). In addition, the complex elements involved in soil erosion, such as climate, soil, topography, and land use, must be identified prior to use of the WEPP model (Foster, 2001).

Phosphorus can be transported as particulate $\mathrm{P}$ (PP) through erosion, or as dissolved P (DP) through leaching and overland flow. Traditionally, control of PP in runoff was used to improve water quality (Sharpley et al., 1994). However, recent research has shown that DP influences eutrophication. A flow weighted annual DP runoff concentration of $1 \mathrm{mgL}^{-1}$ is recommended for discharge from sewage treatment facilities (USEPA, 1986).

The presence of nitrogen $(\mathrm{N})$ in surface water may also be of concern. The most common form of $\mathrm{N}, \mathrm{NH}_{4}-\mathrm{N}$, may result from the biological breakdown of manure. Its loss into surface waters can result in poisoning of aquatic organisms if the concentration is greater than $2.5 \mathrm{mg} \mathrm{L}^{-1}$ (USEPA, 1986).

Previous studies have focused on factors that influence nutrient transport, such as surface runoff and drainage (Steinheimer et al., 1998), timing of manure application, soil conditions, topography, vegetative cover (Edwards and Daniel, 1994), and method of manure application (Heathman et al., 1995). The length of time that has elapsed since manure application was also found to affect runoff nutrient concentrations (Gilley and Eghball, 2002).

The relationship between nutrient content, and physical and chemical properties of manure has been investigated (Moral et al., 2005). Electrical conductivity (EC) was shown to be an easily determined parameter for estimation of total $\mathrm{N}, \mathrm{NH}_{4}-\mathrm{N}$ and potassium in pig slurries. Lugo-Ospina et al. (2005) identified procedures for predicting the nutrient content of diary manure and estimating soluble $\mathrm{P}$ losses in runoff following land application of manure.

Several computer models have been developed to predict soil erosion and corresponding nutrient losses from agricultural runoff, for example, GWLF (Schneiderman et al., 2002), SMDR (Gérard-Marchant et al., 2005), and SWAT (DiLuzio and Arnold, 2004). However, a full understanding of the nutrient transport process is difficult, which limits the accuracy and reliability of many process-oriented models. In addition, large data input requirements may restrict the use of comprehensive simulation models (Bhattacharya and Solomatine, 2000). Therefore, researchers have sought alternative predictive procedures. During the last decade, Artificial Neural Networks (ANNs) have been used as an alternative modeling method.
Inspired by networks of biological neurons, ANN models contain multiple layers of simple computing nodes that operate as nonlinear summing devices. Weighted links interconnect these nodes. Each weight is adjusted when measured data are presented to the network during a "training" process. Successful training can result in an ANN model that performs tasks such as predicting an output value, classifying an object, approximating a function, recognizing a pattern in multifactorial data, and completing a known pattern (Suen and Eheart, 2003). Among many ANN architectures, a multilayer feed-forward network with a BP algorithm is commonly used for forecasting and parameter estimation (Kolehmainen et al., 2001). It has been shown that ANN can generate the nonlinearity in the environment represented by nutrient discharge from agricultural fields. However, few studies have been conducted to implement ANN tools for quantitative estimation of nutrient transport (Li et al., 2004).

Nonlinear relationships between eroded soil and selected runoff nutrient constituents ( $\mathrm{DP}$ and $\mathrm{NH}_{4}-\mathrm{N}$ ) and water quality characteristics were defined in this study using ANN and a BP algorithm. Information from ANN analyses and simulations can be used to assist water resources managers and others assessing water quality management programs (Govindaraju and Rao, 2000). The specific objectives of this study were to: (1) relate soil erosion and DP and $\mathrm{NH}_{4}-\mathrm{N}$ concentrations in runoff to selected hydrologic and water quality factors, and (2) evaluate ANN model performance for predicting soil erosion and runoff nutrient transport.

\section{Materials and methods}

\subsection{Field study site characteristics}

Field tests were conducted from June 2002 to May 2003 at the University of Nebraska Rogers Memorial Farm located $18 \mathrm{~km}$ east of Lincoln, NE in Lancaster County. Sharpsburg silty clay loam soil (fine, smectitic, and mesic Typic Argiudoll) at the site contained $11 \%$ sand, $54 \%$ silt, and $35 \%$ clay, and $18.5 \mathrm{~g} \mathrm{~kg}^{-1}$ of organic $C$ in the top $15 \mathrm{~cm}$ of the soil profile. The soil developed in loess under prairie vegetation and had a mean slope of $7 \%$. The site had been cropped using a grain sorghum (Sorghum bicolor (L.) Moench), soybean (Glycine $\max$ (L.) Merr.), winter wheat (Triticum aestivum L. cv. Pastiche) rotation, under a no-till management system, and was planted to soybean during the 2001-cropping season. From June 2002 to May 2003, $686 \mathrm{~mm}$ of precipitation was received at the experimental location. Mean annual precipitation is $711 \mathrm{~mm}$.

\subsection{Plot preparation}

The tillage plots were disked up and down the slope on 31 May 2002, and the entire plot area was then planted along the contour to corn using a 76-cm row spacing with a target population of 69,000 plants ha ${ }^{-1}$. Herbicide was applied as needed during both 2002 and 2003 to prevent weed growth. The study area was harvested using a combine on 17 September 2002 (107 days following manure application).

Beef cattle manure was collected from a feedlot operation at the University of Nebraska Agricultural Research and 
Development Center near Ithaca, NE. Manure was applied on 30 May 2002 at a wet rate of $56.1 \mathrm{Mg} \mathrm{ha}^{-1}$, using the estimated $\mathrm{N}$ rate required to achieve a target corn yield of $9.4 \mathrm{Mgha}^{-1}$. Application rates were determined assuming $40 \% \mathrm{~N}$ availability during the first year following application for beef cattle manure (Eghball and Power, 1999).

\subsection{Rainfall simulation procedures}

Rainfall simulation procedures identified by the National Phosphorus Research Project (NPRP) were employed in this study (Sharpley and Kleinman, 2003). A portable rainfall simulator was used to apply rainfall to paired plots. Two rain gauges were placed along the outer edge of each plot, and one rain gauge was located between the plots. To provide more uniform antecedent soil water conditions between treatments, water was first added to the plots with a hose until runoff began. The simulator was then used to apply rainfall for 30-min at an intensity of $70 \mathrm{~mm} \mathrm{~h}^{-1}$.

Water used in the rainfall simulation tests was obtained from a well used for irrigation. Samples for water quality analyses were collected each day from a storage tank prior to testing to determine input water quality characteristics. Reported nutrient concentration values represent the difference between runoff measurements and concentrations in the irrigation well water.

Field rainfall simulation tests were initiated 4 (6-3-02) days, 32 (7-1-02) days, 62 (7-31-02) days, 123 (9-30-02) days, and 354 (5-19-03) days following manure application. Twelve plots, each $0.75-\mathrm{m}$ wide $\times 2-\mathrm{m}$ long, were established along the contour for use during each of the five test intervals. Thus, tests were conducted during this study on 60 separate plots. The 12 plots examined during a selected test period were not used during subsequent investigations. The plots were not protected from natural rainfall between test intervals and runoff resulting from natural precipitation events was not monitored. For each test group and following the initial rainfall event, plots were covered with tarps to prevent the input of natural rainfall. Two additional rainfall simulation tests were then conducted for the same duration and intensity at approximately 24-h intervals.

\subsection{Runoff sample collection and analysis}

Plot borders consisted of a sheet metal lip that emptied into a collection trough. The trough extended across the bottom of each plot and diverted runoff into aluminum washtubs. After completion of a rainfall simulation event, the washtubs were weighed to determine total runoff volume. The runoff was then agitated to maintain suspension of solids. Two runoff samples were obtained for water quality measurements and two additional samples were collected for sediment analysis. Centrifuged and filtered runoff samples were analyzed for DP (Murphy and Riley, 1962), and $\mathrm{NO}_{3}-\mathrm{N}$ and $\mathrm{NH}_{4}-\mathrm{N}$ using a Lachat system (Zellweger Analytics, Milwaukee, WI). Non-centrifuged samples were analyzed for total phosphorus (TP) (Johnson and Ulrich, 1959), total nitrogen (TN) (Tate, 1994), pH, and EC. The two samples obtained for sediment analysis were dried in an

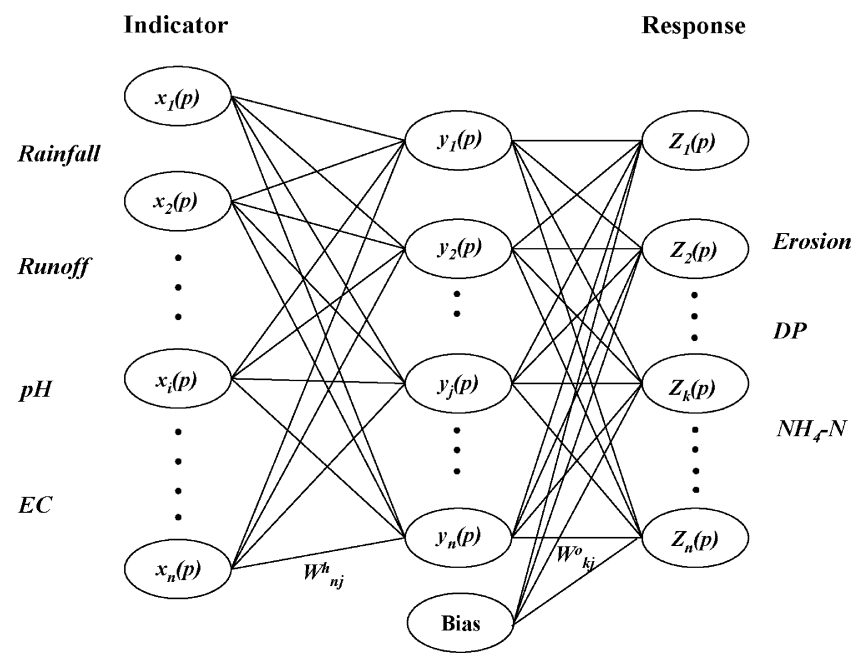

Fig. 1 - A schematic structure of a neural network is shown. Input values, $x_{1}(p)-x_{n}(p)$, provided through an input layer; $y_{1}(p)-y_{n}(p)$ are the weighted sum of all its input $\left(\sum x_{n}(p) W_{j i}^{h}\right) ; w_{j i}^{h}$ and $w_{k j}^{o}$ are weights used to compute the hidden and output layers; $Z_{1}(p)-Z_{n}(p)$ are computed output values, $f\left(y_{n}(p)\right.$; and $f$ are nonlinear activation or transfer functions, e.g., logistic sigmoid, linear, threshold, Gaussian or hyperbolic tangent.

oven at $105^{\circ} \mathrm{C}$ and then weighed to determine sediment content. Gilley et al. (submitted for publication) provide additional information concerning the field experimental program.

\subsection{Neural network and backpropagation algorithm}

The NeuralWorks Professional II/PLUS (NeuralWorks, Carnegie, Pennsylvania) software, Version 5.22, was used to create the multilayer feed-forward neural network, and this package allows users to develop their own model by providing selected network and control parameters.

A popular architecture used with neural networks is the multilayered perceptron (MLP), which can be trained by a BP algorithm (BP). The BP network typically is organized as a set of interconnected layers of artificial neurons, input, hidden and output layers (Fig. 1).

When a neural group is provided with data through the input layer, the neurons in this first layer propagate the weighted data and bias randomly selected through the hidden layers. Once the net sum at a hidden node is determined, an output response is provided at the node using a transfer function. The newly generated signal is then transferred forward to a subsequent layer (e.g., either a hidden or output layer). The same response procedure is repeated for each hidden node (Kuo et al., 2007).

The term "backpropagation" refers to the way the error computed at the output layer of the ANN is propagated into the hidden layer where all computations are made. The gradient of the error of a network is calculated using BP (Eq. (1)) and the network's modifiable weights. The root mean square error (RMSE) measures the difference between model estimation 
and measurement (German et al., 1992):

$\operatorname{RMSE}=\frac{1}{n} \sum_{i=1}^{n}\left(\hat{Z}\left(x_{i}\right)-Z\left(x_{i}\right)\right)^{2}$

where $Z\left(x_{i}\right)$ and $\hat{Z}\left(x_{i}\right)$ represent the measured and the predicted values, respectively, and $n$ is the size of the population.

Dependent input variables (rainfall, runoff, $\mathrm{pH}$ and $\mathrm{EC}$ ) and independent output variables (erosion, $\mathrm{DP}$ and $\mathrm{NH}_{4}-\mathrm{N}$ ) are provided for training of the neural network. The input and output process elements (PEs) are fixed by the particular user application, but the number of hidden PEs must be specified. Network performance can be considered a quadratic function of the number of hidden PEs; an increase or decrease in the number of PEs could enhance model performance.

The initial default parameter values include the number of hidden neurons (0), momentum (0.4), learning rule (Deltarule), learning coefficient ratio (0.5), transfer function (TanH), and convergence criterion (training goal: $10^{-3}$ ). The weights and biases are iteratively adjusted during training using the momentum method to minimize network error.

The input and output data consisted of different parameters with various physical meanings, units, and ranges. Therefore, all variables were standardized to ensure equal attention during the training process. During the preprocessing stage, input and output data were scaled in the range of 0.1-0.9. The data were then entered into the initialized network to prevent larger numbers (erosion, runoff, and rainfall) from suppressing smaller values (DP, $\mathrm{NH}_{4}-\mathrm{N}, \mathrm{pH}$, and $\mathrm{EC}$ ) and to prevent premature saturation of hidden nodes, which impedes the learning process.

Networks trained with experimental data that adequately represent the overall characteristics of the critical physical processes will achieve higher generalization ability. To accomplish this goal, the 435 data points used in this study (each 145 data points of soil erosion, rainfall and runoff) were divided into three subsets: a training set ( $72 \%$ of the total), a validation set ( $8 \%$ of the total), and a test set $(20 \%$ of the total). In this study, the $k$-fold cross-validation method was used to improve the generalization of the network and prevent over-fitting (Bishop, 1995). All data were randomly divided into $k=12$ subsets of equal size and different network architecture and selected parameters were identified and trained. Each time one of subsets from the training set was left out during the training, but the omitted subset was used for validation. This procedure was repeated until no further decrease in error occurred among 12 subsets. After training and validation, the network architecture having the smallest error over 12 subsets was selected and then evaluated using the test set.

Network parameters were evaluated to achieve the best architectural performance for the ANN. Parameters included number of hidden layers and PEs; transfer functions (linear, TanH, sigmoid, Digital Neural Network Architecture (DNNA), sine); update rules (Delta-rule, Normalize cumulative delta, Extended Delta-Bar-Delta, Quickpro, and Delta-Bar-Delta); and number of iterations. Detailed information concerning the ANN definition and function can be found in a software manual written by NeuralWare (1996).

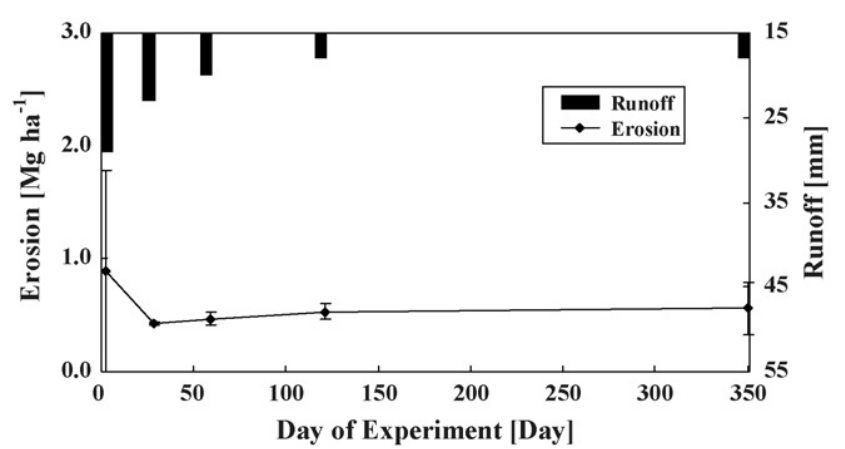

Fig. 2 - Runoff and erosion measurements versus time since application of beef cattle manure. Vertical bars represent one standard deviation of the mean value.

The RMSE between the network outputs (predicted) and the target outputs (measured) were computed. If RMSE was found to be stable and within established limits at the end of each learning period, the final parameter set was determined and post-processing (non-normalization) was conducted.

\section{Results and discussion}

\subsection{Field experimental results}

Mean measured runoff for the field experimental tests on the no-till cattle manure treatments was $20 \mathrm{~mm}$ and erosion was $0.31 \mathrm{Mg} \mathrm{ha}^{-1}$, compared to $22 \mathrm{~mm}$ and $0.52 \mathrm{Mgha}^{-1}$ for tilled conditions. Runoff and erosion measurements obtained during the experimental study are shown in Fig. 2. Since measured runoff rates were similar between no-till and tilled conditions, the trends relating to nutrient concentration should also be applicable to nutrient load.

\subsubsection{Dissolved phosphorus in runoff}

For the no-till cattle manure treatments, DP concentrations in runoff ranged from 0.50 to $2.85 \mathrm{mgL}^{-1}$ (Fig. 3). Concentrations of DP on the treatments where cattle manure was incorporated

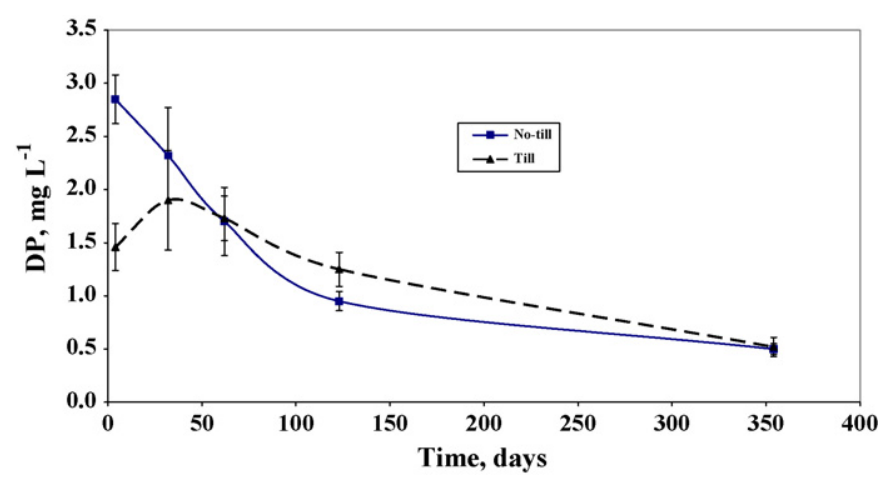

Fig. 3 - Dissolved phosphorus (DP) concentrations of runoff versus time since manure application for the experimental treatments. Vertical bars represent one standard deviation of the mean value. This information was obtained from Gilley et al. (submitted for publication). 


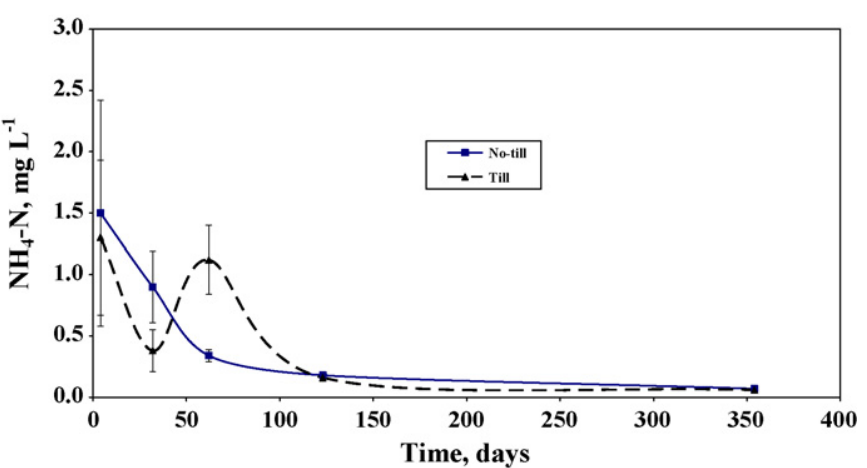

Fig. 4 - Concentrations of $\mathrm{NH}_{4}-\mathrm{N}$ in runoff versus time since manure application for the experimental treatments. Vertical bars represent one standard deviation of the mean value. This information was obtained from Gilley et al. (submitted for publication).

varied from 0.52 to $1.90 \mathrm{mgL}^{-1}$. Runoff concentrations of DP for the tests initiated during the first two test periods were significantly greater on the no-till than the tilled plots.

\subsubsection{Ammonium in runoff}

The $0.27 \mathrm{~g} \mathrm{~kg}^{-1}$ of $\mathrm{NH}_{4}-\mathrm{N}$ in cattle manure at the time of application was relatively small. Therefore, substantial bacterial decomposition appeared to have occurred soon after the addition of cattle manure to cause the $1.50 \mathrm{mgL}^{-1}$ of $\mathrm{NH}_{4}-\mathrm{N}$ (the largest value obtained for any of the test dates) measured on the initial test date (Fig. 4). Significant reductions in $\mathrm{NH}_{4}-\mathrm{N}$ runoff concentrations were found among the first three study dates. On the final test date, mean $\mathrm{NH}_{4}-\mathrm{N}$ concentrations in
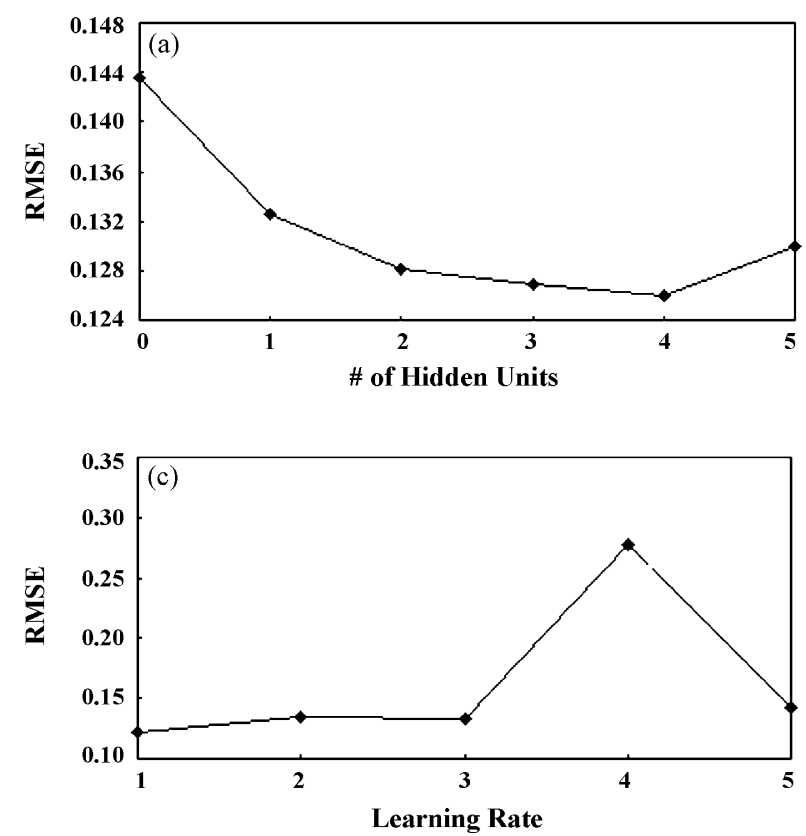

Table 1 - Correlation coefficients of nutrient constituents with hydrologic and water quality characteristics ${ }^{a}$

\begin{tabular}{lrrrrrr} 
& $\mathrm{DP}$ & $\mathrm{PP}$ & $\mathrm{TP}$ & $\mathrm{NO}_{3}-\mathrm{N}$ & $\mathrm{NH}_{4}-\mathrm{N}$ & \multicolumn{1}{c}{$\mathrm{TN}$} \\
\hline Erosion & -0.175 & -0.104 & -0.183 & 0.012 & 0.123 & 0.057 \\
Rainfall & -0.107 & -0.055 & -0.107 & -0.229 & 0.032 & -0.100 \\
Runoff & -0.188 & -0.313 & -0.281 & 0.256 & -0.126 & -0.186 \\
$\mathrm{DP}$ & 1.000 & 0.285 & 0.915 & -0.139 & 0.537 & 0.534 \\
$\mathrm{PP}$ & 0.285 & 1.000 & 0.647 & -0.069 & 0.352 & 0.327 \\
$\mathrm{TP}$ & 0.915 & 0.647 & 1.000 & -0.140 & 0.575 & 0.563 \\
$\mathrm{NO}_{3}-\mathrm{N}$ & -0.139 & -0.069 & -0.140 & 1.000 & -0.098 & 0.456 \\
$\mathrm{NH}_{4}-\mathrm{N}$ & 0.537 & 0.352 & 0.575 & -0.098 & 1.000 & 0.525 \\
$\mathrm{TN}$ & 0.534 & 0.327 & 0.563 & 0.456 & 0.525 & 1.000 \\
$\mathrm{EC}$ & 0.616 & 0.375 & 0.647 & 0.162 & 0.665 & 0.866 \\
$\mathrm{pH}$ & -0.351 & -0.256 & -0.387 & 0.004 & -0.580 & -0.429 \\
\hline
\end{tabular}

a A correlation coefficient is significant at the $95 \%$ confidence level if $\mid$ correlation $\mid>0.195$ for $n=360$.

runoff on the no-till cattle manure treatments were reduced to $0.07 \mathrm{mg} \mathrm{L}^{-1}$.

Concentrations of $\mathrm{NH}_{4}-\mathrm{N}$ in runoff for the tilled cattle manure treatments ranged from 0.06 to $1.30 \mathrm{mgL}^{-1}$. Although significant differences in $\mathrm{NH}_{4}-\mathrm{N}$ concentrations were measured among test dates $(p$-value $=0.0002)$, no consistent trends between consecutive test periods were apparent. Concentrations of $\mathrm{NH}_{4}-\mathrm{N}$ in runoff were reduced substantially on the final two test dates, probably as a result of reductions in the mineralization of organic $\mathrm{N}$.

Runoff $\mathrm{NH}_{4}-\mathrm{N}$ concentrations were significantly greater under no-till conditions for the test interval beginning 32 days following manure application $\left(0.90 \mathrm{mgL}^{-1}\right)$. However, significantly larger concentrations of $\mathrm{NH}_{4}-\mathrm{N}$ were found on the tilled treatments initiated 62 days after manure application
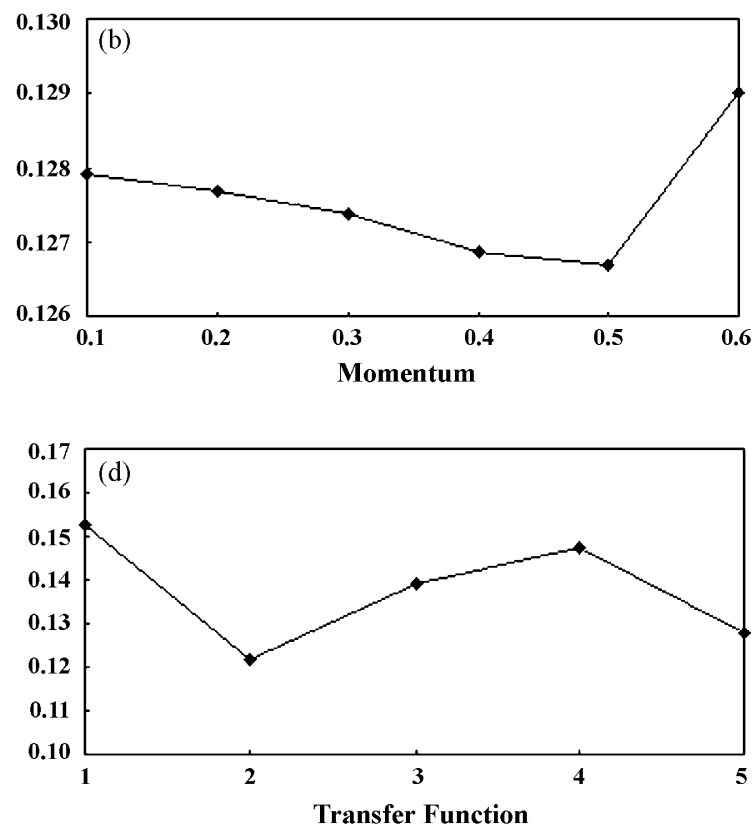

Fig. 5 - (a-d) Responses of governing factors ((a) the number of hidden units, (b) momentum, (c) learning rate, and (d) transfer function) represented by the RMSE. $x$-Axis in (c) represents learning rates, which are Delta-rule (1), Normalize cumulative delta (2), Extended Delta-Bar-Delta (3), Quickpro (4), and Delta-Bar-Delta (5), and x-axis in (d) represent transfer functions, which are linear (1), TanH (2), sigmoid (3), DNNA (4), and sine (5). 
(1.12 $\left.\mathrm{mgL}^{-1}\right)$. Tillage did not significantly influence $\mathrm{NH}_{4}-\mathrm{N}$ runoff concentrations from the cattle manure treatments on the other test dates.

\subsubsection{Effects of runoff and water quality factors on} nutrient concentrations in runoff

The effects of selected environmental factors on nutrient concentrations in runoff were determined (Table 1). The concentrations of nutrient constituents in runoff were not significantly correlated to erosion. Only $\mathrm{NO}_{3}-\mathrm{N}$ content of runoff was significantly related to rainfall. Concentrations of $\mathrm{PP}, \mathrm{TP}$ and $\mathrm{NO}_{3}-\mathrm{N}$ in overland flow were significantly correlated to runoff. Each of the nutrient constituents was significantly related to EC. The only nutrient constituent that was not significantly correlated to $\mathrm{pH}$ was $\mathrm{NO}_{3}-\mathrm{N}$.
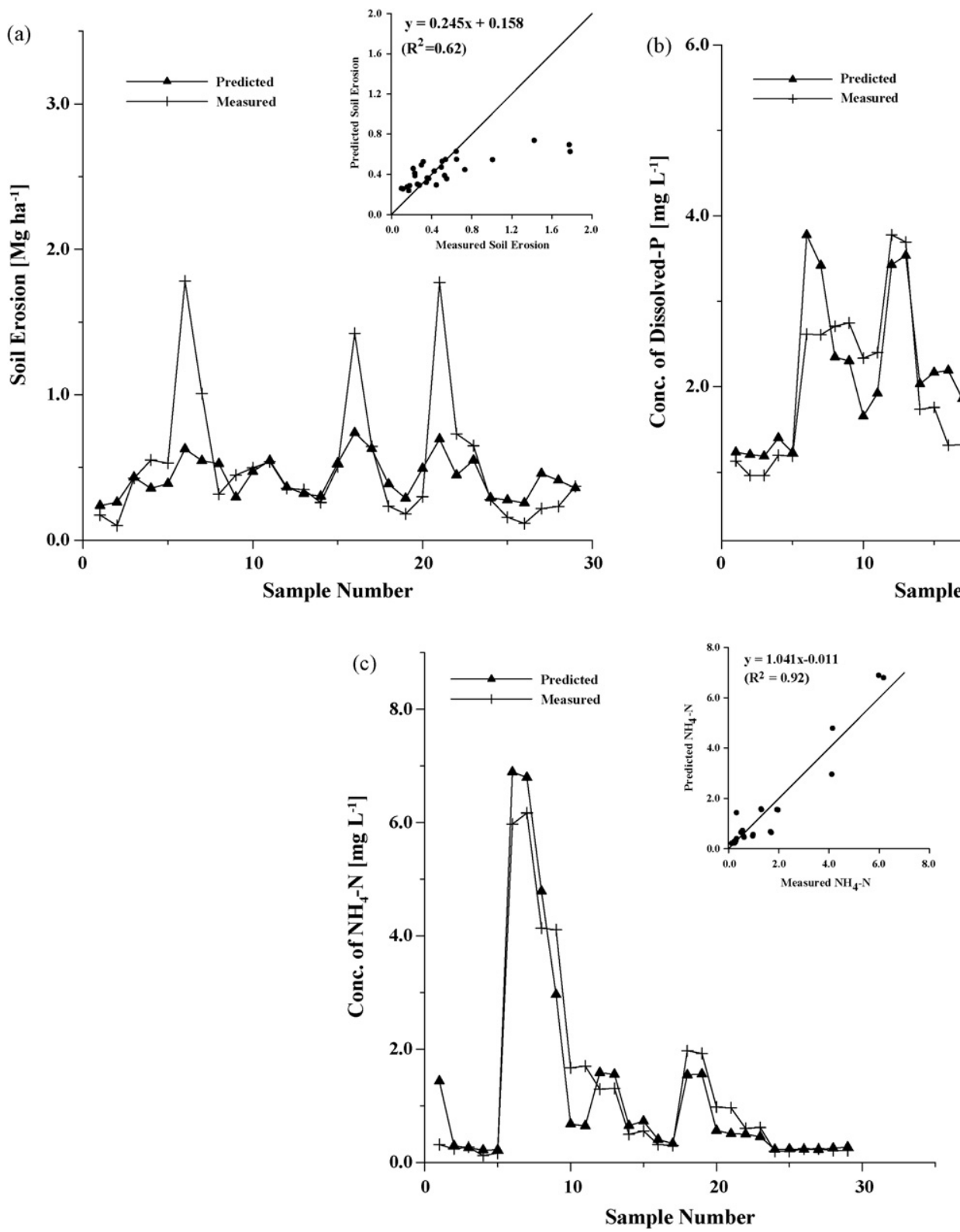

\subsection{Performance of ANNs}

Soil erosion, DP, and $\mathrm{NH}_{4}-\mathrm{N}$ were selected as response variables for the ANN evaluation. These nutrient parameters were chosen because concentration limits for $\mathrm{DP}$ and $\mathrm{NH}_{4}-\mathrm{N}$ in runoff have been established (USEPA, 1986). In addition, it was thought to be important to evaluate ANN procedures for both $\mathrm{P}$ and $\mathrm{N}$ constituents.

Fig. $5(a-d)$ shows the responses of trained and tested DP networks for DP estimation to changes of governing factors (number of hidden PEs, momentum, learning rate, and transfer function). Many studies have shown that a neural network with one hidden layer is capable of approximating any finite nonlinear function with very high accuracy (Schalkoff, 1997) and this is consistent with the present study (not shown).

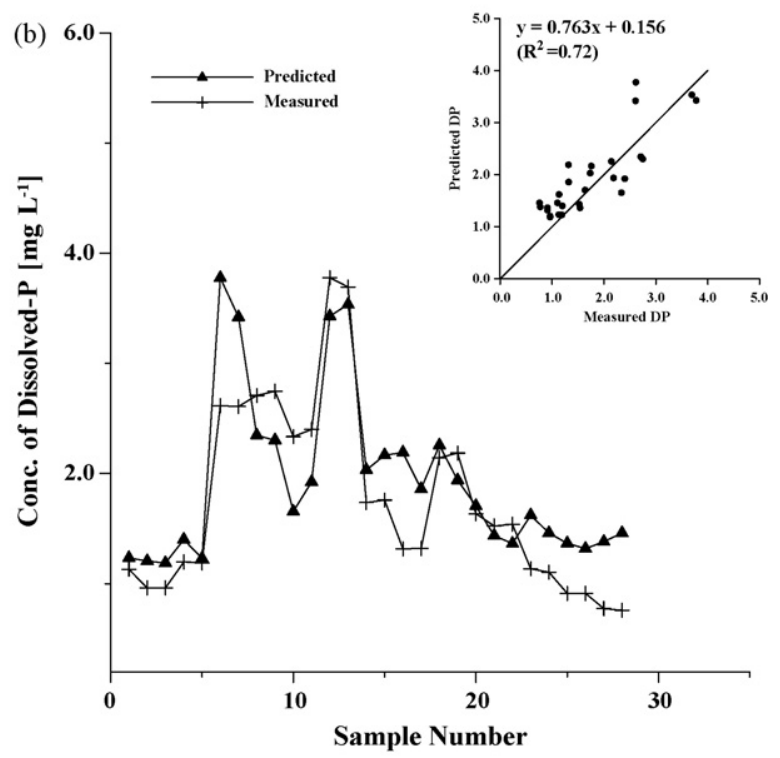

Fig. 6 - (a) Comparative results for soil erosion with scatter plots (top right side) between predicted and measured values. (b) Comparative results for dissolved $\mathrm{P}$ with scatter plots (top right side) between predicted and measured values. (c) Comparative results for $\mathrm{NH}_{4}-\mathrm{N}$ with scatter plots (top right side) between predicted and measured values. 


\begin{tabular}{|c|c|c|c|}
\hline & Soil erosion & DP & $\mathrm{NH}_{4}-\mathrm{N}$ \\
\hline Architecture type & $2-1-1$ & $3-3-1$ & $3-2-1$ \\
\hline Learning rate & 0.5 & 0.3 & 0.7 \\
\hline Momentum & 1.0 & 0.7 & 0.4 \\
\hline Learning rule & Delta & Delta & Delta \\
\hline Transfer function & TanH & TanH & TanH \\
\hline Iterations & 50,000 & 50,000 & 50,000 \\
\hline RMSE & 0.093 & 0.1217 & 0.081 \\
\hline$R^{2}$ & 0.62 & 0.72 & 0.92 \\
\hline
\end{tabular}

The experimental results showed a clear trend relating to the generalization ability of ANN and the number of hidden PEs. As the number of hidden PEs increased, model performance improved (Fig. 5(a)). However, more than four hidden PEs did not improve the simulation results and the best results were obtained using four hidden PEs. Momentum did not have a significant influence on simulation results (Fig. 5(b)) as shown by the small changes of RMSE. A high learning rate resulted in increasing accuracy of training and testing by changing the weight vector significantly from one cycle to another. However, a learning rate greater than one did not provide better results (Fig. 5(c)). The hyperbolic tangent (TanH) function produced the best results among the five transfer functions (Fig. 5(d)).

The relationship among the driving variables (runoff, rainfall, $\mathrm{pH}$, and EC) and the output variables (soil erosion, DP, and $\mathrm{NH}_{4}-\mathrm{N}$ ) was identified using ANNs. Simulation results estimating soil erosion, $\mathrm{DP}$ and $\mathrm{NH}_{4}-\mathrm{N}$ concentrations are plotted in Fig. 6(a-c). The scatter plots between predicted and measured values of soil erosion, $\mathrm{DP}$, and $\mathrm{NH}_{4}-\mathrm{N}$ concentrations (normal-transformed) after 50,000 iterations of the learning procedure are also shown in Fig. 6 .

The model derived from ANN analyses did not provide reliable estimates for the three largest erosion measurements as shown in Fig. 6(a). As a result, the regression equation obtained when predicted and measured erosion values were compared had a slope of only 0.25 from the 1:1 scatter plots on lefttop corner of Fig. 6 (a). Thus, ANN analysis underestimated the amount of eroded soil. This can be explained by greater opportunity for TN and TP to be dissolved and transported by overland flow rather than attached to soil eroded since the applied manure remained on the soil surface.

The 1:1 scatter plots of predicted versus measured concentrations of DP and $\mathrm{NH}_{4}-\mathrm{N}$ were closely aligned and provided coefficient of determination values of 0.72 and 0.92, respectively, which indicates that ANN model trained by BP was able to provide accurate estimates of nutrient contents. The best performance was achieved from the feed-forward connection (number of input layer-hidden layer-output layer), 2-1-1, 3-2-1, and 3-3-1, respectively. Additional information concerning the governing factors is provided in Table 2.

\section{Conclusions}

Manure may serve as a source of nutrients for crop production and an amendment to improve soil characteristics. However, runoff from agricultural areas on which manure is applied may be an environmental concern. The physical mechanisms responsible for sediment and nutrient transport by overland flow are complex and difficult to represent mathematically. Multilayer ANN trained with a BP computational algorithm may serve as an alternative for estimating soil and nutrient transport from land application areas.

Development of a simulation model using ANN techniques requires a training process. Field runoff and nutrient transport data collected by Gilley et al. (submitted for publication) from a land application site near Lincoln, Nebraska, USA were used for model calibration. Approximately $80 \%$ of the available field data obtained over a 1-year period were used for training/validation and $20 \%$ were selected for testing. Using ANN calculations, erosion was related to rainfall and runoff characteristics, and concentrations of DP and $\mathrm{NH}_{4}-\mathrm{N}$ in overland flow were related to measurements of runoff, EC and $\mathrm{pH}$.

The ANN-derived model did not provide accurate estimates for the largest erosion values. However, the 1:1 scatter plots of predicted versus measured concentrations of DP and $\mathrm{NH}_{4}-\mathrm{N}$ were closely aligned. Coefficient of determination calculations between predicted and measured values of DP and $\mathrm{NH}_{4}-\mathrm{N}$ were 0.72 and 0.92 , respectively. Therefore, the experimental results suggest that the models derived using ANN procedures can be used to provide reliable estimates of nutrient concentrations in runoff from land application areas in this study.

Runoff, EC and pH can be easily measured under real-time conditions. In comparison, runoff samples for nutrient analyses must be taken to the laboratory for subsequent analyses. If models can be developed from ANN analyses using readily obtained input parameters collected during a runoff event, it may be possible to implement remedial measures in realtime if established concentration or total maximum daily load requirements are exceeded.

\section{REFERENCES}

Bhattacharya, B., Solomatine, D.P., 2000. Application of artificial neural network in stage-discharge relationship. In: Proceedings of the 4th International Conference on Hydro-informatics, Iowa City, IA, pp. 1-7.

Bishop, C.M., 1995. Neural Networks for Pattern Recognition, 1st Edition. Oxford, Clarendon.

Czapar, G.F., Laflen, J.M., McIsaac, G.F., McKenna, D.P., 2005. Proceedings of the Effect of Erosion Control Practices on Nutrient Loss The Gulf Hypoxia and Local Water Quality Concerns Workshop, Ames, IA, 26-28 September.

DiLuzio, M., Arnold, J.G., 2004. Formulation of a hybrid calibration approach for a physically based distributed model with NEXRAD data input. J. Hydrol. 298, 136-154.

Edwards, D.R., Daniel, T.C., 1994. Quality of runoff from fescuegrass plots treated with poultry litter and inorganic fertilize. J. Environ. Qual. 23, 579-584.

Eghball, B., Power, J.F., 1999. Phosphorus and nitrogen-based manure and compost applications: corn production and soil phosphorus. Soil Sci. Soc. Am. J. 63 (4), 895-901.

Foster, G.R., 2001. Keynote: soil erosion prediction technology for conservation planning. In: Stott, D.E., Mohtar, R.H., Steinhartdt, G.C. (Eds.), Proceedings of the Sustaining the Global Farm. Selected papers from the 10th International Soil Conservation Organization Meeting. Purdue University and the USDA-ARS National Soil Erosion Research Laboratory, 24-29 May 1999. 
Gérard-Marchant, P., Walter, M.T., Steenhuis, T.S., 2005. Simple models for phosphorus loss from manure in runoff. J. Environ. Qual. 34 (3), 872-876.

German, S., Bienenstock, E., Doursat, R., 1992. Neural networks and the bias/variance dilemma. Neural Comput. 4, 1-58.

Gilley, J.E., Eghball, B., 2002. Residual effects of compost and fertilizer applications on nutrients in runoff. Trans. ASAE 45 (6), 1905-1910.

Gilley, J.E., Eghball, B., Marx, D.B., submitted for publication. Nutrient concentrations of runoff during the year following manure application. Trans. ASAE, 50.

Govindaraju, R.S., Rao, A.R., 2000. Artificial Neural Networks in Hydrology. Kluwer Academic Publishers, Amsterdam.

Heathman, G.C., Sharpley, A.N., Smith, S.J., Robinson, J.S., 1995. Poultry litter application and water quality in Oklahoma. Fertil. Res. 40, 165-173.

Johnson, C.M., Ulrich, A., 1959. Analytical methods for use in plant analysis. Agric. Exp. Stn. Bull. 766, 26-78.

Kolehmainen, M., Martikainen, H., Ruuskanen, J., 2001. Neural networks and periodic components used in air quality forecasting. Atmos. Environ. 35, 815-825.

Kuo, J.-T., Hsieh, M.-H., Lung, W.-S., She, N., 2007. Using artificial neural network for reservoir entrophication prediction. Ecol. Model. 200, 171-177.

Lane, L.J., Nearing, M.A., 1989. USDA-Water Erosion Prediction Project-Hillslope Profile Version. NSERL Report No. 2. US Department of Agriculture, Agriculture Research Service, W. Lafayette, IN.

Li, J., Yoder, R.E., Odhiambo, L.O., Zhang, J., 2004. Simulation of nitrate distribution under drip irrigation using artificial neural networks. Irrig. Sci. 23 (1), 29-37.

Lugo-Ospina, A., Dao, T.H., Van Kessel, J.A., Reeves-III, J.B., 2005. Evaluation of quick tests for phosphorus determination in dairy manures. Environ. Pollut. 135 (1), 155-162.

Moral, R., Perez-Murcia, M.D., Perez-Espinosa, A., Moreno-Caselles, J., Paredes, C., 2005. Estimation of nutrient values of pig slurries in Southeast Spain using easily determined properties. Waste Manage. 25 (7), 719-725.

Murphy, J., Riley, J.P., 1962. A modified single solution method for the determination of phosphate in natural waters. Anal. Chem. Acta 27, 31-36.

National Research Council Committee on Animal Nutrition, 1993. Building a North American Feed Information System. Online book. Available at http://www.nap.edu/catalog/9296.html. Accessed April 2007.
NeuralWare Inc., 1996. Software manual of NeuralWorks Plus/II.

Renard, K.G., Freimund, J.R., 1994. Using monthly precipitation data to estimate the R-factor in the revised USLE. J. Hydrol. 157, 287-306.

Renard, K.G., Foster, G.R., Weesies, G.A., McCool, D.K., Yoder, D.C., 1997. Predicting soil erosion by water: A guide to conservation planning with the Revised Universal Soil Loss Equation (RUSLE). Agric. Handbook No. 703. U.S. Gov. Print. Office, Washington, DC.

Schalkoff, R.J., 1997. Artificial Neural Networks. McGraw-Hill, New York, pp. 146-188.

Schneiderman, E.M., Pierson, D.C., Lounsbury, D.G., Zion, M.S., 2002. Modeling the hydrochemistry of the Cannonsville watershed with Generalized Watershed Loading Functions (GWLF). J. Am. Water Resour. Assoc. 38 (5), 1323-1347.

Sharpley, A.N., Kleinman, P., 2003. Effect of rainfall simulator and plot scale on overland flow and phosphorus transport. J. Environ. Qual. 32, 2172-2179.

Sharpley, A.N., Chapra, S., Wedepohl, R., Sims, J.T., Daniel, T.C., Reddy, K., 1994. Managing agricultural phosphorus for protection of surface waters: issues and options. J. Environ. Qual. 23 (3), 437-451.

Soil Conservation Service, 1994. Waste utilization standard and specifications. SCS Tech. Practice Code 633. SCS, Stillwater, OK.

Steinheimer, T.R., Scoggin, K.D., Kramer, L.A., 1998. Agricultural chemical movement through a field-size watershed in Iowa: surface hydrology and nitrate losses in discharge. Environ. Sci. Technol. 32, 1048-1052.

Suen, J.P., Eheart, J.W., 2003. Evaluation of neural networks for modeling nitrate concentration in rivers. J. Water Resour. Plan. Manage. 129 (6), 505-510.

Tate, D.F., 1994. Determination of nitrogen in fertilizer by combustion: collaborative study. J. AOAC Int. 77, 829-839.

United States Environmental Protection Agency (USEPA), 1986. Quality criteria for water. Office of Water Regulation and Standards. EPA-440/586-001.

United States Environmental Protection Agency (USEPA), 2000. Ecoregional nutrient criteria. Office of Water, USEPA. Available at http://www.epa.gov/waterscience/criteria/nutrient/ ecoregions/. Accessed May 2007.

Wischmeier, W.H., Smith, D.D., 1978. Predicting rainfall erosion losses: a guide to conservation planning. Agric. Handbook No. 282. US Department of Agriculture, Washington, DC. 